\title{
Alt Ekstremite ve Kalça Merkezi Sabit Tutularak Uygulanan Üst Ekstremite Y Dinamik Denge Testi Güvenirlik Çalışması
}

\author{
Reliability Study of the Upper Quarter Y Dynamic Balance Test Applied by \\ Holding the Lower Extremity and Hip Center Fixed
}

\author{
${ }^{1}$ Cenab TÜRKERİ \\ ${ }^{2}$ Bilgihan BÜYÜKTAŞ \\ ${ }^{2}$ Barışcan ÖZTÜRK
}

${ }^{1}$ Çukurova Üniversitesi, Hareket ve Antrenman Bilimleri Anabilim Dalı

${ }^{2}$ Çukurova Üniversitesi, Sağlık Bilimleri Enstitüsü, Beden Eğitimi ve Spor Anabilim Dalı

Yazıșma Adresi

Corresponding Address:

Dr. Öğr. Üyesi Cenab Türkeri

ORCID: 0000-0003-4850-9810

Çukurova Üniversitesi, Hareket ve Antrenman Anabilim Dalı Başkanlığ

BESYO, Bilimleri

E-posta: cturkeri@cu.edu.tr

Geliş Tarihi (Received): 24.01.2020 Kabul Tarihi (Accepted): 29.04.2020

\section{öz}

Bu çalışma üst ekstremite $Y$ dinamik denge testinin alt ekstremiteyi ve kalça merkezini sabit tutarak tam standart uygulamasının ölçüm güvenirliğini belirlemek amacıyla yapılmıştır. Çalışmaya branşında $9,42 \pm 5,27$ yıllık spor geçmişine sahip, yaş ortalamaları $21,40 \pm 2,63$ yıl, boy ortalamaları $174 \pm 0,09 \mathrm{~cm}$, ağırlık ortalamaları $67,95 \pm 12,38 \mathrm{~kg}$ olan farklı spor branşlarından toplam 203 gönüllü (kadın=72, erkek=131) sporcu katılmıştır. Üst Ekstremite $Y$ dinamik denge testi test-retest skorları arasındaki ilişki Pearson Momentler Çarpımı Korelasyon Katsayısı ile bulunmuş, ayrıca testin sınıf içi güvenirliğinin belirlenmesinde Intraclass Correlation Coefficient testi (ICC) uygulanmıştır (\%95 confidence intervals). Elde edilen bulgular doğrultusunda toplam değerler olan sağ composite1-composite2 $r=0,87\left(r^{2}=0,77\right)$ olarak ve sol composite1composite2 $r=0,89\left(r^{2}=0,79\right)$ olarak yüksek ilişki tespit edilmiştir. Üst ekstremite $Y$ dinamik denge testi ilk ve ikinci ölçümleri sınıf içi güvenirlik katsayısı en yüksek sağ $=0,93$ ve sol $=0,94$ olarak tespit edilmiştir. Üst ekstremite $Y$ dinamik denge testinin, ölçüm standardı şınav pozisyonunda, inklinometre ile kontrol edilerek, bacaklar ve kalça merkezi birlikte sabit olarak sağlanmıs şekilde uygulanmasının güvenirliğinin oldukça yüksek olduğu anlaşılmıştır. Testin bu şekilde kullanılması daha güvenilir sonuçlar elde edilmesini sağlayacaktır. Bu test verileri kullanılarak, omurga ve üst ekstremite hareketliliği, omuz eklemi instabilitesi, üst ekstremitenin esnekliği ve denge performansının değerlendirilmesi yapılabilir. Bunun yanı sıra hem bilimsel araştırmalarda hem de uygulamalarda kullanılmak üzere sporcunun üst ekstremite denge asimetrisi belirlenebilir ve sakatlıklara yatkınlık düzeyi söylenebilir.

Anahtar Kelimeler: Denge asimetrisi, Üst ekstremite, Omuz eklemi instabilitesi, Omurga hareketliliği

\section{ABSTRACT}

This study was conducted to determine the measurement reliability of the full standard application of the upper extremity $Y$ dynamic balance test by keeping the lower extremity and hip center stable. In our study, a total of 203 volunteers from different sports branches with a sports age of $9.42 \pm 5.27$ years, average age $21.40 \pm 2.63$ years, height $174 \pm 0.09 \mathrm{~cm}$, weight $67.95 \pm 12.38 \mathrm{~kg}$ athletes participated (female $=72$, male $=131$ ). The relationship between the upper extremity $Y$ dynamic balance test-retest scores was found with the Pearson moments product correlation coefficient. In addition, intraclass correlation coefficient testing (ICC) was performed to determine the Internal consistency reliability of the Test ( $95 \%$ confidence intervals). Among the first and second measurements of the upper extremity $Y$ dynamic balance test, the highest intraclass reliability coefficient was determined as right $=0.93$ and left $=0.94$. It has been found that the reliability of applying the upper extremity $Y$ dynamic balance test in the push-up position of the measurement standard, controlled with an inclinometer, with the legs and hip center fixed, is quite high. Using this test data, the evaluation of vertebrae and upper extremity mobility, shoulder joint instability, flexibility of the upper extremity and balance performance can be performed. In addition, the upper extremity balance asymmetry of the athlete can be determined and the level of susceptibility to injuries can be used for both scientific research and applications.

Key Words: Balance asymmetry, Upper extremity, Shoulder joint instability, Vertebral mobility 


\section{GíRIŞ}

Denge becerisi iyi bir performans sergilemek ve performansı artırmak için son derece gerekli bir parametre olarak bilinmektedir (Ateş ve diğ. 2017). Sporcuların sportif performanslarını meydana getirme de önemli bir etken olan dinamik denge, aynı zamanda da sporcuların yaralanmalarında performansı belirleyici ve önleyici bir etkiye sahip motorsal bir beceridir (Butler ve diğ. 2013; Gribble ve diğ. 2012; Plisky ve diğ. 2009). Sportif performansın gelişiminde ve korunmasında oldukça öneme sahip olan denge becerisinin sporculardaki mevcut durumunun bilinmesi sporcuların gelişimi açısından oldukça önemli rol oynamaktadır. Ancak çok sayıda spor kurumu, sporcuların denge düzeylerini belirlemek için uygun tarama testlerinin eksik olduğunu belirtmektedir (Batt ve diğ. 2004; Fuller ve diğ. 2007).

Genel olarak denge ölçümleri için sahada ve laboratuvar ortamlarında kullanılabilecek kolay ve ekonomik test sayısı oldukça azdır. Olan testler de genellikle alt ekstremiteyi doğrudan ölçüm düzeneğinde incelemektedir (Bahar, 2019; Koçak, 2019; Chimera ve diğ. 2015; Güçhan ve diğ. 2014). Ancak üst ekstremite ve gövdenin de ölçüm düzeneğinde olması ve ölçülmesi gerekmektedir. Üst ekstremite ve gövdenin (omurga) dinamik denge ölçümlerine dahil edildiği az sayıda test bulunmaktadır.

Literatürde üst ekstremite denge düzeyini belirlemek için kullanılan testler, kapalı kinetik zincir denge testi ve tek kol siçrama testidir (Falson ve diğ. 2002; Goldbeck, 2000; Roush ve diğ. 2007). Ancak üst ekstremite dinamik denge düzeyini belirlemede kullanılan bu testler, geniş ve düz bir alanda rahat bir şekilde yapılmasından dolayı sporcuların yeterince sabitlik sınırlarına ulaşmalarını sağlamamakta ve ayrıca dengenin diğer önemli bileşenleri olan mobilite (hareketlilik), propriosepsiyon ve sabitlik becerilerini içermemektedir (Gorman ve diğ. 2012).

Bu testlerin sınırl11ıklarından dolayı sporcuların fiziksel performansını ölçmek, denge becerilerini karşılaştırmak ve sporcuların sakatlık durumlarını belirlemek için üst ekstremite Y dinamik denge testi geliştirilmiştir (Plisky ve diğ. 2006; Hale ve diğ. 2007; Olmsted ve diğ. 2002). Yapılan üst ekstremite dinamik denge testlerinin aksine üst ekstremite Y dinamik denge testinde denek test sırasında maksimum düzeyde zorlanmaktadır. Test uygulanırken sporcular dar bir destek tabanı üzerinde tek el şınav pozisyonunda skapular sabitliği en yüksek seviyede korurken, torasik rotasyon ve core stabilite bileşenlerini devreye alarak, dengeyi kaybetmeden diğer eli ile hareketli olarak blokları en uzak noktaya taşımaya çalışmaktadır (Gorman ve diğ. 2012). Y dinamik denge testi Plisky ve diğ. (2006) tarafından yıldız dinamik denge testi (Star Excursion Balance Test) yerine geliştirilmiş bir testtir. Y dinamik denge testi, Yıldız dinamik denge testine göre kullanımı daha kolay ve daha doğru sonuç verdiği düşünülmektedir. Y dinamik denge testi alt ekstremite ve üst ekstremite için farklı şekillerde uygulanmaktadır. Çalışmamızda ölçüm güvenirliğini incelediğimiz üst ekstremite Y dinamik denge testi (alt ekstremite ve kalça merkezi sabit tutularak), omurga hareketliliği, omuz eklemi instabilitesi ve üst ekstremitenin esnekliğini kullanarak sporcudan veri toplanmasını sağlamakta ve buna göre sporcunun denge asimetrisi ve sakatlıklara yatkınlığ hakkında tahmini bilgi vermektedir.

Sporcunun üst ekstremite dinamik denge düzeyinin iyi olması, performansını olumlu etkileyebildiği gibi postural salınımını düzenlemesine yardımcı olacaktır. Ayrıca oluşabilecek sakatlıkların önleyebilmesinde etkili olduğu düşünülmektedir. Genel olarak üst ekstremite $\mathrm{Y}$ dinamik denge testi uygulamasında alt ekstremite ve kalça merkezi, üst ekstremitenin ve gövdenin rotasyonuna destek verecek şekilde serbest bırakılmakta ve bu durum önceki çalı̧̧malardaki gözlemlerimize göre asıl değerlendirilmek istenen üst ekstremitenin doğru ölçülmesini olumsuz etkilemektedir. $\mathrm{Bu}$ bağlamda literatürde daha önce üst ekstremite dinamik denge becerisini alt ekstremiteyi ve kalça merkezini tam sabit tutarak (cephe pozisyonunda, inklinometre ile düzgün duruş sağlanıp) ölçüm alınmamıştır. Çalışmamız bu yönüyle literatüre katkı sağlayacağı da varsayılarak üst ekstremite Y Dinamik Denge Testinin (the upper quarter Y dynamic 
balance test) alt ekstremite ve kalça sabitlenerek (inklinometre ile düzgün duruş sağlanıp) uygulandığında güvenilir sonuçlar verip vermeyeceğini belirlemek amacıyla yapılmıştır.

\section{YÖNTEM}

Araştırma Grubu: Çukurova Üniversitesi BESYO Performans Ölçüm Laboratuvarında yapılan çalışmaya, Çukurova üniversitesinde okuyan sporcu öğrenciler ve üniversite spor tesislerine antrenmanlara gelen tablo 2'de belirtilen farklı branşlardan sporcular alınmıştır. Katılımcılar her hangi bir yaralanması ve hastalığı bulunmadığını beyan eden, branşında $9,42 \pm 5,27$ yıllık spor geçmişine sahip, yaş ortalamaları $21,40 \pm 2,63$ yıl, boy ortalamaları $174 \pm 0,09 \mathrm{~cm}$, ağırlık ortalamaları $67,95 \pm 12,38 \mathrm{~kg}$ olan farklı spor branşlarında (tablo 2) toplam 203 gönüllü sporcudan oluşmaktadır (kadın=72, erkek=131). Sporculara yapılacak çalışmanın ne olduğu ve çalışma protokolü hakkında bilgi verilmiş, kabul edenlere çalışmanın amaç ve yöntemlerini belirten onam formu imzalatılmıştır. Çukurova Üniversitesi girişimsel olmayan klinik araştırmalar etik kurulundan tpl: 95/ kr: 57 izin nosu ile onay alınmıştır. Tüm katılımcılardan Helsinki Bildirgesine uygun olarak imzalı onam formu alınarak çalışma gerçekleştirilmiştir.

Tablo 1. Cinsiyete Göre Sporcuların Demografik Özellikleri

\begin{tabular}{lccc} 
& Kadın n=72 & Erkek n=131 & Toplam n=203 \\
& $\overline{\mathbf{x}} \pm$ Ss & $\overline{\mathbf{x}} \pm \mathbf{S s}$ & $\overline{\mathbf{x}} \pm \mathbf{S s}$ \\
\hline Yaş (yıl) & $20,83 \pm 2,34$ & $21,72 \pm 2,73$ & $21,40 \pm 2,63$ \\
Boy (cm) & $166 \pm 0,71$ & $179 \pm 0,72$ & $174 \pm 0,93$ \\
Vücut Ăğırlı̆̆ı (kg) & $56,75 \pm 7,11$ & $74,11 \pm 10,14$ & $67,95 \pm 12,38$ \\
Spor Yaşı (yıl) & $9,02 \pm 5,11$ & $9,63 \pm 5,36$ & $9,42 \pm 5,27$ \\
Kol Boyu (cm) & $71,83 \pm 4,41$ & $79,52 \pm 4,84$ & $76,79 \pm 5,96$ \\
BMI & $20,53 \pm 1,95$ & $23,17 \pm 2,33$ & $22,24 \pm 2,54$ \\
\hline
\end{tabular}

\section{Veri Toplama Araçları:}

Y dinamik denge test materyali: Üst Ekstremite Y Dinamik Denge (the upper quarter y dynamic balance test) Test materyali, merkez bir platforma (denge noktası) bağlı medial, inferolateral ve superolateral uzanma yönlerine sahip üç adet PVC borudan ve bu borulara yerleştirilmiş üç adet PVC bloktan oluşmaktadır. Platformun doğrusal hattına dikey olarak yan yönlerindeki (inferolateral ve posterolateral) borular kendi arasında $45^{\circ}$, medial yöndeki borudan ise $135^{\circ}$ olacak şekilde konumlandırılmıştır. Sporcuların erişebildikleri mesafeyi belirlemek için platforma bağlı olan medial, inferolateral ve superolateral yönlerdeki boruların üzerinde $1 \mathrm{~mm}$ aralıklarda mesafe ölçer bulunmaktadır.

Üst Ekstremite Y Dinamik Denge Testi Uygulama Protokolü: Test, deneklerin (dominant ve non-dominant) her iki kolu için uygulanmıştır. Deneklerin hareketleri kısıtlamayacak spor giysileriyle, Y denge test platformunun üzerinde eli merkez noktada sabit bir şekilde şınav pozisyonunda (cephe pozisyonu) dengede dururken, ayaklar omuz genişliğinde, bacaklar ve kalça merkezi birlikte sabit olarak bulunmaktadır. Sporcu daha sonra bir eli ile sabit duruşunu koruyarak, alt ekstremite ve kalça merkezinden destek almadan sadece üst ekstremite ile uzanır ve eliyle medial $\left(0^{\circ}\right)$, inferolateral $\left(45^{\circ}\right)$ (diğer elin altından içeriden) ve superolateral $\left(45^{\circ}\right)$ yönlere doğru parmak ucu ile blokları itmiştir. Sporcu her seferinde sabit duruş noktasına eli yere değdirmeden geri getirerek uygulamayı yapmıştır. Test her üç yönde (medial, inferolateral, superolateral) ikişer kez tekrar edildikten sonra ölçüm ortalamaları alınıp normalleştirme formülü kullanılmıştır (şekil 1). 


\section{Medial+İnferolateral+Superolateral}

\section{3x Arm Length}

Şekil 1. Ölçümlerin Normalleştirme Formülü

Verilerin Toplanması: Katılımcıların demografik özellikleri için araştırmacılar tarafından hazırlanan anket formu kullanılmıştır. Formda kişinin; cinsiyet, yaş, boy, ağırlık, kol boyu, spor yaşı ve vücut kitle indeksi-body mass index (BMI-VKİ) verileri kaydedilmiştir. Sporcuların hastalık, yaralanma, ameliyat varlığı, kullandığı ilaçlar, alerji ve beslenme durumları sorgulanmış, herhangi bir sorunu olmayanlar antrenman yapmadıkları bir günün ardından önce ilk ölçüme alınmış ve ardından iki hafta sonra yine antrenman yapmadıkları günün ardından aynı gün ve saatlerde ikinci ölçümleri aynı araştırmacı ekip tarafından alınmıştır.

Verilerin Analizi: İstatistiksel analizler, SPSS 22.0 programı kullanılarak yapılmıştır. Deneklerin demografik özellikleri tanımlayıcı istatistikler ile analiz edilmiştir. Sonuçlar aritmetik ortalama \pm standart sapma ( $\overline{\mathrm{x}} \pm$ ss) olarak verilmiştir. Verilerin normallik dağılımı için Kolmogorov-Smirnov testi uygulanmış ve normal dağılım gösterdiği bulunmuştur. Üst Ekstremite Y dinamik denge test skorları arasındaki ilişki Pearson Momentler Çarpımı Korelasyon Katsayısı ile bulunmuştur. Ayrıca iki kez aynı gruba aynı test uygulandığından dolayı (test-retest) testin sınıf içi güvenirliğinin belirlenmesinde Intraclass Correlation Coefficient (ICC) testi de kullanılmıştır (\% 95 confidence intervals).

\section{BULGULAR}

Tablo 2'de sporcuların branşlara göre dağılımı verilmiştir. Buna göre takım sporları n=95 (\%47) ve bireysel sporlar $\mathrm{n}=108(\% 53)$ olduğu görülmektedir.

Tablo 2. Sporcuların Branşlara Göre Dağılımı

\begin{tabular}{|c|c|c|c|}
\hline$n=203$ & BRANŞ & $\mathbf{n}$ & $\%$ \\
\hline \multirow{4}{*}{$\begin{array}{l}\text { Takım Spor Branşları } \\
\text { n=95 }(\% 47)\end{array}$} & Futbol & 39 & 19,2 \\
\hline & Basketbol & 16 & 7,9 \\
\hline & Voleybol & 16 & 7,9 \\
\hline & Hentbol & 24 & 11,8 \\
\hline \multirow{9}{*}{$\begin{array}{l}\text { Bireysel Spor Branşları } \\
n=108(\% 53)\end{array}$} & Taekwondo & 16 & 7,9 \\
\hline & Atletizm & 19 & 9,4 \\
\hline & Cimnastik & 15 & 7,4 \\
\hline & Karate & 5 & 2,5 \\
\hline & Tenis & 8 & 3,9 \\
\hline & Yüzme & 20 & 9,9 \\
\hline & Kick Boks & 9 & 4,4 \\
\hline & Güreş & 16 & 7,9 \\
\hline & TOPLAM & 75 & 100,0 \\
\hline
\end{tabular}

Tablo 3'te çalışmaya katılan sporcuların cinsiyetlere göre üst ekstremite Y dinamik denge ölçümleri verilmiştir. Bunlardan toplam değerler olan sağ composite ilk ölçüm $82,44 \pm 10,66 \mathrm{~cm}$ ve ikinci ölçüm $83,96 \pm 10,88 \mathrm{~cm}$, sol composite ilk ölçüm $81,22 \pm 12,08 \mathrm{~cm}$ ve ikinci ölçüm $82,80 \pm 12,68 \mathrm{~cm}$ olduğu bulunmuştur. 
Tablo 3. Kadın ve Erkek Sporcuların 1.ve 2. Ölçüm (test-retest) Üst Ekstremite Y dinamik Denge Skorları

\begin{tabular}{|c|c|c|c|c|c|c|c|}
\hline & \multirow[t]{2}{*}{$\mathrm{n}=\mathbf{2 0 3}$} & \multicolumn{2}{|c|}{ Kadın } & \multicolumn{2}{|c|}{ Erkek } & \multicolumn{2}{|c|}{ Toplam } \\
\hline & & $\begin{array}{c}\text { 1.Ölçüm } \\
\overline{\mathbf{X}} \pm \text { Ss }\end{array}$ & $\begin{array}{c}\text { 2. Ölçüm } \\
\overline{\mathbf{X}} \pm \text { Ss }\end{array}$ & $\begin{array}{l}\text { 1.Ölçüm } \\
\overline{\mathbf{X}} \pm \text { Ss }\end{array}$ & $\begin{array}{c}\text { 2. Ölçüm } \\
\overline{\mathbf{X}} \pm \text { Ss }\end{array}$ & $\begin{array}{l}\text { 1.Ölçüm } \\
\overline{\mathbf{X}} \pm \text { Ss }\end{array}$ & $\begin{array}{c}\text { 2. Ölçüm } \\
\overline{\mathbf{X}} \pm \text { Ss }\end{array}$ \\
\hline & Medial & $103,83 \pm 19,59$ & $104,35 \pm 21,56$ & $110,38 \pm 24,90$ & $108,65 \pm 26,69$ & $108,06 \pm 23,32$ & $107,13 \pm 25,02$ \\
\hline & İnferolateral & $74,95 \pm 10,41$ & $79,75 \pm 11,08$ & $87,03 \pm 14,03$ & $86,25 \pm 11,15$ & $82,53 \pm 14,20$ & $83,95 \pm 11,53$ \\
\hline & Superolateral & $54,65 \pm 15,10$ & $56,68 \pm 12,65$ & $58,55 \pm 16,50$ & $63,06 \pm 18,96$ & $57,17 \pm 16,09$ & $60,81 \pm 17,24$ \\
\hline & Composite & $78,70 \pm 9,68$ & $80,26 \pm 10,39$ & $84,50 \pm 10,65$ & $85,99 \pm 10,64$ & $82,44 \pm 10,66$ & $83,96 \pm 10,88$ \\
\hline \multirow{4}{*}{$\begin{array}{l}\mathbf{S} \\
\mathbf{O} \\
\mathbf{L}\end{array}$} & Medial & $97,83 \pm 22,14$ & $95,56 \pm 22,94$ & $107,11 \pm 25,31$ & $106 \pm 27,61$ & $103,82 \pm 24,58$ & $102,77 \pm 26,54$ \\
\hline & İnferolateral & $79,52 \pm 11,79$ & $80,69 \pm 13,00$ & $86,06 \pm 11,55$ & $88,89 \pm 11,76$ & $83,74 \pm 12,02$ & $85,98 \pm 12,80$ \\
\hline & Superolateral & $52,31 \pm 14,51$ & $54,61 \pm 15,39$ & $58,15 \pm 18,69$ & $62,42 \pm 20,87$ & $56,07 \pm 17,51$ & $59,65 \pm 19,43$ \\
\hline & Composite & $76,55 \pm 11,84$ & $76,95 \pm 12,17$ & $83,77 \pm 11,48$ & $86,02 \pm 11,81$ & $81,21 \pm 12,08$ & $82,80 \pm 12,68$ \\
\hline
\end{tabular}

Tablo 4'te çalışmaya katılan sporcuların test-retest ölçüm üst ekstremite Y dinamik denge sınıf içi güvenirlik katsayıları verilmiştir. Üst ekstremite Y dinamik denge testi ilk ve ikinci ölçümleri sınıf içi güvenirlik katsayısı en yüksek sağ $=0,93$ ve sol=0,94 ICC bulunmuştur.

Tablo 4. Sporcuların 1. ve 2. Ölçüm (test-retest) Y Dinamik Denge Test Skorlarının Güvenirlik Sonuçları

\begin{tabular}{lllcc}
\hline $\mathbf{n = 2 0 3}$ & & $\mathbf{I C C}$ & $\mathbf{9 5 \%} \mathbf{C I}$ & SEM \\
\hline \multirow{3}{*}{ SAĞ } & Medial & 0,89 & $0,86-0,92$ & $1,64-1,76$ \\
& Inferolateral & 0,77 & $0,72-0,84$ & $0,99-0,81$ \\
& Superolateral & 0,65 & $0,54-0,73$ & $1,13-1,21$ \\
\hline \multirow{2}{*}{ SOL } & Composite & $\mathbf{0 , 9 3}$ & $0,91-0,95$ & $0,75-0,76$ \\
& Medial & 0,90 & $086-0,92$ & $1,73-1,86$ \\
& Inferolateral & 0,89 & $0,86-0,92$ & $0,84-0,90$ \\
& Superolateral & 0,89 & $0,86-0,92$ & $1,23-1,36$ \\
& Composite & $\mathbf{0 , 9 4}$ & $0,92-0,96$ & $0,85-0,89$
\end{tabular}

ICC: Intra Class Coefficient, CI: Confidence Interval, SEM: Standart Error Means

Tablo 5'te çalışmaya katılan sporcuların üst ekstremite Y dinamik denge güvenirlik sonuçları verilmiştir. Tabloya göre, sağdan alınan ölçümlerde; medial1-medial2 r=0,80, $(\mathrm{p}=0,00), \quad(\mathrm{r} 2=0,65)$, inferolateral1-inferolateral2 $\mathrm{r}=0$,66, $(\mathrm{p}=0,00),(\mathrm{r} 2=0,44)$, superolateral1-superolateral2 $\mathrm{r}=0,48,(\mathrm{p}=0,00),(\mathrm{r} 2=0,23)$ composite1-composite $2 \mathrm{r}=0,87,(\mathrm{p}=0,00)$, (r2=0,77) olarak bulunmuştur. Soldan alınan ölçümlerde; medial1-medial2 r=0,81, (p=0,00), (r2=0,66), inferolateral1inferolateral2 $\mathrm{r}=0,80,(\mathrm{p}=0,00),(\mathrm{r} 2=0,65)$, superolateral1-superolateral2 $\mathrm{r}=0,80,(\mathrm{p}=0,00),(\mathrm{r} 2=0,65)$ composite1composite $2 \mathrm{r}=0,89,(\mathrm{p}=0,00)$, (r2=0,79) olarak bulunmuştur. 
Tablo 5. Sporcuların Üst Ekstremite Y dinamik Denge 1. Ölçüm ve 2. Ölçüm Korelasyon Tablosu

\begin{tabular}{|c|c|c|c|c|c|c|}
\hline & & & $\begin{array}{l}\text { MEDİAL } \\
2\end{array}$ & $\begin{array}{c}\text { İNFEROLATERAL } \\
2 \\
\end{array}$ & $\begin{array}{c}\text { SUPEROLATERAL } \\
2\end{array}$ & $\begin{array}{c}\text { COMPOSITE } \\
2 \\
\end{array}$ \\
\hline \multirow{8}{*}{ SAĞ } & MEDİAL & $\mathbf{r}$ & $\mathbf{0 , 8 0 9} * *$ & $0,325 * *$ & $-0,29$ &, $582 * *$ \\
\hline & 1 & $\mathbf{p}$ & 0,00 & 0,00 & 0,00 & 0,00 \\
\hline & İNFEROLATERAL & $\mathbf{r}$ & $0,270 * *$ & $0,661 * *$ & $0,201 * *$ &, $547 * *$ \\
\hline & 1 & $\mathbf{p}$ & 0,00 & 0,00 & 0,00 & 0,00 \\
\hline & SUPEROLATERAL & $\mathbf{r}$ & $-0,32$ & 0,06 & $0,482 * *$ & 0,03 \\
\hline & 1 & $\mathbf{p}$ & 0,00 & 0,40 & 0,00 & 0,70 \\
\hline & COMPOSITE & $\mathbf{r}$ & $0,621 * *$ & $0,690 * *$ & ,293** & $\mathbf{0 , 8 7 5} * *$ \\
\hline & 1 & $\mathbf{p}$ & 0,00 & 0,00 & 0,00 & 0,00 \\
\hline \multirow{8}{*}{ SOL } & MEDİAL & $\mathbf{r}$ & $\mathbf{0 , 8 1 2 ^ { * * }}$ & $0,494^{* *}$ & $-0,209$ & $0,626^{* *}$ \\
\hline & 1 & $\mathbf{p}$ & 0,00 & 0,00 & 0,00 & 0,00 \\
\hline & İNFEROLATERAL & $\mathbf{r}$ & $0,509^{* *}$ & $\mathbf{0 , 8 0 5}{ }^{* *}$ & $0,257^{* *}$ & $0,758^{* *}$ \\
\hline & 1 & $\mathbf{p}$ & 0,00 & 0,00 & 0,00 & 0,00 \\
\hline & SUPEROLATERAL & $\mathbf{r}$ & $-0,114$ & $0,327^{* *}$ & $\mathbf{0 , 8 0 8}{ }^{* *}$ & $0,443^{* *}$ \\
\hline & 1 & $\mathbf{p}$ & 0,10 & 0,00 & 0,00 & 0,00 \\
\hline & COMPOSITTE & $\mathbf{r}$ & $0,664^{* *}$ & $0,760^{* *}$ & $0,334^{* *}$ & $0,890^{* *}$ \\
\hline & 1 & p & 0,00 & 0,00 & 0,00 & 0,00 \\
\hline
\end{tabular}

$* * \mathbf{p} \leq \mathbf{0 , 0 1}$
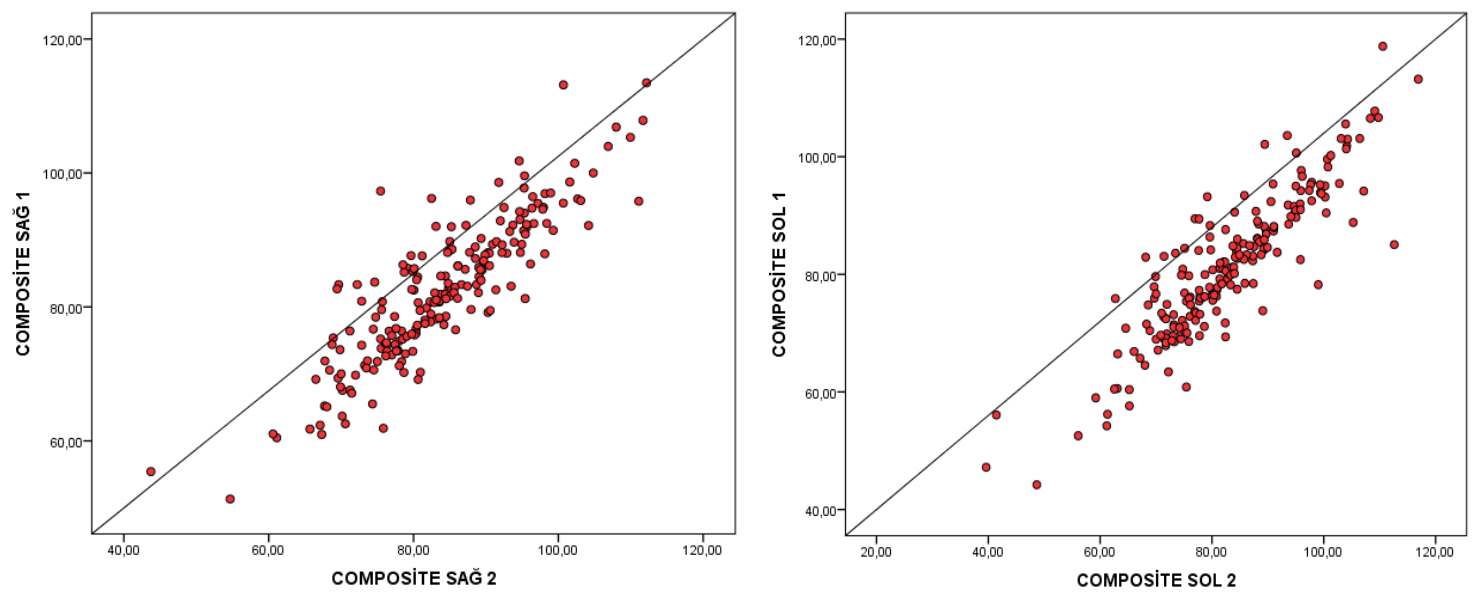

Şekil 2. Să̆ ve sol Composite1-2 ilişki grafiği
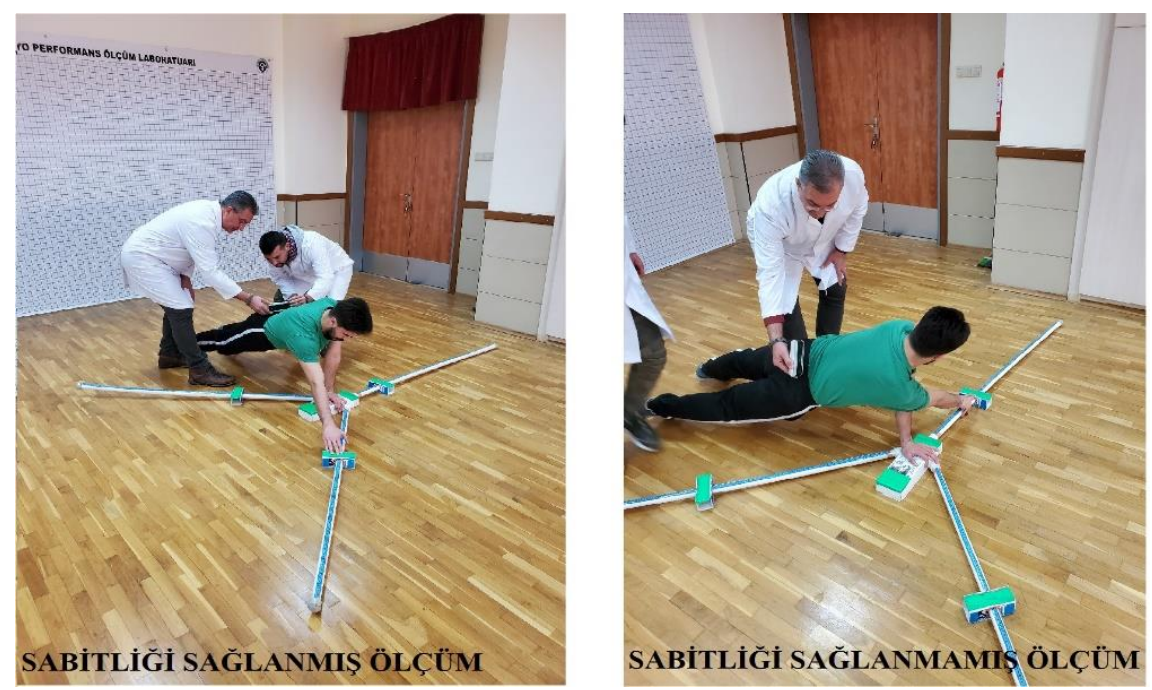

Şekil 3. Sabitliği inklinometre ile sağlanmış ölçüm örneği. 


\section{TARTIŞMA}

$\mathrm{Bu}$ çalışma $\mathrm{Y}$ dinamik denge (the upper quarter $\mathrm{Y}$ dynamic balance test) testi ölçümlerinin daha doğru bir standart uygulama olacağını düşündüğümüz alt ekstremite ve kalça merkezi sabit tutularak uygulanmasının ölçüm güvenilirliğini belirlemek amacıyla yapılmıştır. Elde edilen sonuçlar dikkate alındığında alt ekstremite ve kalça merkezi sabit tutularak uygulanan testin oldukça güvenilir bir ölçme tutarlılığına sahip olduğu söylenebilir.

Testlerde ölçüm güvenirliği araştırmacıların özellikle üzerinde hassasiyet göstermek zorunda oldukları bir kavramdır. Bu sebeple alt ekstremite ve kalça merkezi sabit tutularak yapılacak olan üst ekstremite y dinamik denge testinin ölçüm güvenirliğinin bilinmesi önemlidir. Yapılacak olan çalışmalarda kullanılan ölçüm aleti ya da ölçüm yöntemlerinin kararlı özellik taşıması, hatadan arındırılmış olması ve aynı amaçla yapılacak ikinci bir ölçümde aynı sonuçların elde edilebileceğine güven duyulması yapılacak olan çalışmaların güvenirliğini arttırmaktadır (Ercan, 2004). Literatür incelendiğinde son zamanlarda yapılan sportif ve klinik araştırmalarda sporcuların ya da sedanter bireylerin üst ekstremite fonksiyonel kapasitelerini, denge becerilerini, hareketliliklerini, omuz eklemi instabilitesini ve/veya denge asimetrilerini belirlemek amacıyla üst ekstremite Y Dinamik Denge testi kullanılmıştır (Hazar ve diğ. 2014; Wilson ve diğ. 2013; Amasay ve diğ. 2016; Teyhen ve diğ. 2014).

Çalışmamızda sporcuların üst ekstremite Y dinamik denge skorları sağ taraf ölçümlerinde en iyi ölçümler olarak medial $107,13 \pm 25,02 \mathrm{~cm}$, inferolateral $83,95 \pm 11,53 \mathrm{~cm}$, superolateral $60,81 \pm 17,24 \mathrm{~cm}$ ve composite $83,96 \pm 10,88 \mathrm{~cm}$ olarak bulunmuştur. Sol taraf ölçümlerinde ise medial yönde $103,82 \pm 24,58 \mathrm{~cm}$, inferolateral $85,98 \pm 12,80 \mathrm{~cm}$,

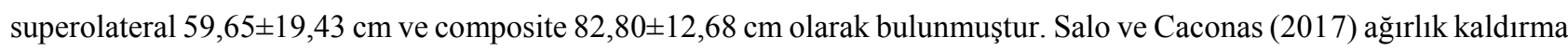
yapan sporcuların üst ekstremite $\mathrm{Y}$ dinamik denge skorlarını inceledikleri çalı̧̧mada sporcuların sağ taraf ölçümlerinde medial $100,74 \pm 4,83 \mathrm{~cm}$, inferolateral $92,37 \pm 11,20 \mathrm{~cm}$, superolateral $67,18 \pm 7,06 \mathrm{~cm}$ ve composite $85,92 \pm 9,06 \mathrm{~cm}$ olarak

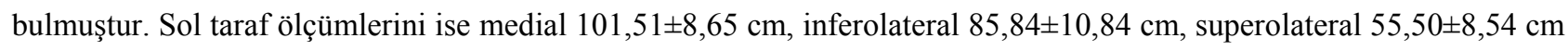
ve composite $85,07 \pm 9.45 \mathrm{~cm}$ olarak bulmuştur. Westrick ve diğ. (2012) üst ekstremite kapalı kinetik zincir performansını değerlendirmede kullandığı üst ekstremite $\mathrm{Y}$ dinamik denge testinde sporcuların en iyi denge skorlarını medial $86,00 \pm 8,00 \mathrm{~cm}$, inferolateral $82,5 \pm 12,2 \mathrm{~cm}$, superolateral $58,2 \pm 8,5 \mathrm{~cm}$ ve composite $85,7 \pm 8,3 \mathrm{~cm}$ olarak bulmuştur. Myers ve diğ. (2017) farklı branştaki sporcuların üst ekstremite Y dinamik denge skorlarını karşılaştırdıkları bir çalışmada sporcuların medial 107,59 $\pm 11,04 \mathrm{~cm}$, inferolateral $85,59 \pm 7,45 \mathrm{~cm}$, superolateral $70,90 \pm 8,26 \mathrm{~cm}$ ve composite 85,14 $\pm 6,30 \mathrm{~cm}$ olarak bulmuştur. Yapılan çalışmalar incelendiğinde, elde edilen üst ekstremite Y dinamik denge skorları ile çalışmamızda elde edilen alt ekstremite ve kalça merkezi sabit olarak uygulanan üst ekstremite Y dinamik denge skorları büyük oranda benzerlik göstermektedir.

Çalı̧̧mamızda alt ekstremite sabit tutularak yapılan üst ekstremite $\mathrm{Y}$ dinamik denge testinin 2 hafta ara ile uygulanması sonucu, üst ekstremite Y dinamik denge testi skorlarının sınıf içi güvenirlik katsayılarının yüksek düzeyde (0.93 ile 0.94) olduğu bulunmuştur. Testin, skor ortalamaları incelendiğinde her iki ölçümde elde edilen skorların birbirine yakın olduğu görülmektedir. Bu durum bize alt ekstremite sabit tutularak yapılan üst ekstremite $\mathrm{Y}$ dinamik denge ölçümlerinde önemli oranda tutarlılık olduğunu göstermektedir. Westrick ve diğ. (2012) üst ekstremite kapalı kinetik zincir performansını değerlendirmede kullandığı üst ekstremite $Y$ dinamik denge testinin güvenirliğini inceledikleri çalışmada dinamik denge katsayılarını yüksek düzeyde $(0,91-0,92)$ bulmuştur. Cramer ve diğ. (2017) üst ekstremite Y dinamik denge testinin güvenirliğini inceledikleri çalışmada dinamik denge katsayılarını yüksek düzeyde $(0,96-0,99)$ bulmuştur. Gorman ve diğ. (2012) alt ekstremite serbest olarak yaptıkları Y dinamik denge testinin güvenirliğini inceledikleri bir çalışmada dinamik denge güvenirlik katsayılarını yüksek düzeyde $(0,94-0,95)$ bulmuştur. Cramer ve diğ. (2017) modifiye edilmiş üst ekstremite Y dinamik denge testinin güvenirliğini inceledikleri çalışmada dinamik denge güvenirlik katsayılarını yüksek 
düzeyde (0,98-1,00) bulmuştur. Yapılan çalışmalar incelendiğinde, elde edilen sınıf içi güvenirlik katsayıları ile çalışmamızda elde edilen sınıf içi güvenirlik katsayıları büyük oranda benzerlik göstermektedir.

\section{SONUÇ}

Çalışmamızda elde ettiğimiz sonuçlar dikkate alındığında, üst ekstremite Y dinamik denge testinin, ölçüm standartı normal şınav pozisyonunda, dengede dururken, ayaklar omuz genişliğinde, bacaklar ve kalça merkezi birlikte sabitliği inklinometre ile kontrol edilerek sağlanmış şekilde uygulanmasının sporcularda güvenirliğinin oldukça yüksek olduğu anlaşılmıştır. Çalışmamız testin normal kullanımında göz ardı edilebilen alt ekstremite ve kalça merkezi sabitliğini dikkatli bir şekilde sağlayarak uygulandığında güvenirliğinin yüksek olduğunu göstermiştir. Bu şekilde yapılan uygulamanın daha geçerli olup olmadığı başka bir çalışmanın konusudur. Ancak alt ekstremite ve kalça merkezinin sabitliğinin sağlanmasıyla elde edilecek test verileri kullanılarak, omurga ve üst ekstremite hareketliliği, omuz eklemi instabilitesi, üst ekstremitenin esnekliği ve denge performansının değerlendirilmesi yapılabilir.

\section{ÖNERİLER}

Daha sonra yapılacak olan çalışmalara fikir vermesi amacıyla alt ve üst ekstremite Y dinamik denge testinin güvenirliğinin birlikte incelenip, denge asimetrilerinin belirlenmesi tavsiye edilebilir. Ayrıca, ilerleyen süreçlerde geçerliliği ve güvenirliği yüksek olan farklı dinamik denge testleri ile alt ekstremite ve kalça merkezi sabitliği sağlanarak uygulanan üst ekstremite Y dinamik denge testinin geçerliğinin karşılaştırılması daha doğru olacaktır.

\section{KAYNAKLAR}

1. Amasay, T., \& Hall, G. A., Shapiro S, Ludwig, K. (2016). The Relation between Scapular Dyskinesis and the Upper Quarter Y-Balance Test. Int J Anat Appl Physiol, 2(2), 20-25.

2. Ateş, B., Çetin, E., Yarım, İ. (2017). Kadın sporcularda denge yeteneği ve denge antrenmanları. Gaziantep Üniversitesi Spor Bilimleri Dergisi, 2(2), 66-79. ISSN: 2536-5339.

3. Bahar, A. (2019). Y denge test performansı ile hamstring esnekliği arasındaki ilişki. Gaziantep Üniversitesi Spor Bilimleri Dergisi, 4(1), 93-103. Doi: 10.31680/gaunjss.514993

4. Batt, M. E., Jaques, R., Stone, M. (2004). Preparticipation examination (screening): practical issues as determined by sport: a United Kingdom perspective. Clinical Journal of Sport Medicine, 14(3), 178-182. ISSN: 1050-642X.

5. Butler, R. J., Lehr, M. E., Fink, M. L., Kiesel, K. B., Plisky, P. J. (2013). Dynamic balance performance and noncontact lower extremity injury in college football players: an initial study. Sports health, 5(5), 417-422. Doi: 10.1177/1941738113498703

6. Chimera, N. J., Smith, C. A., Warren, M. (2015). Injury history, sex, and performance on the functional movement screen and Y balance test. Journal of athletic training, 50(5), 475-485. Doi: 10.4085/1062-6050-49.6.02

7. Cramer, J., Quintero, M., Rhinehart, A., Rutherford, C., Nasypany, A., May, ve diğ. (2017). Exploration of score agreement on a modified upper quarter Y-balance test kit as compared to the upper quarter Y-balance test. International journal of sports physical therapy, 12(1), 117.

8. Ercan, İ., Kan, İ. (2004). Ölçeklerde güvenirlik ve geçerlik. Uludağ Üniversitesi Tip Fakültesi Dergisi, 30(3), 211-216. ID: JA68ZN85VB.

9. Falsone, S. A., Gross, M. T., Guskiewicz, K. M., Schneider, R. A. (2002). One-arm hop test: reliability and effects of arm dominance. Journal of Orthopaedic \& Sports Physical Therapy, 32(3), 98-103. Doi: 10.2519/jospt.2002.32.3.98

10. Fuller, C. W., Ojelade, E. O., Taylor, A. (2007). Preparticipation medical evaluation in professional sport in the UK: theory or practice? British journal of sports medicine, 41(12), 890-896. Doi: 10.1136/bjsm.2007.038935.

11. Goldbeck, T. G., Davies, G. J. (2000). Test-retest reliability of the closed kinetic chain upper extremity stability test: a clinical field test. Journal of Sport Rehabilitation, 9(1), 35-45. Doi: 10.1123/jsr.9.1.35

12. Gorman, P. P., Butler, R. J., Plisky, P. J., \& Kiesel, K. B. (2012). Upper Quarter Y Balance Test: reliability and performance comparison between genders in active adults. The Journal of Strength \& Conditioning Research, 26(11), 3043-3048.

13. Gribble, P. A., Hertel, J., Plisky, P. (2012). Using the star excursion balance test to assess dynamic postural-control deficits and outcomes in lower extremity injury: a literature and systematic review. Journal of athletic training, 47(3), 339-357. Doi: 10.4085/1062-6050-47.3.08.

14. Güçhan, Z., Özaydınlı, E. I., Demirel, S., Yüzlü, V., Nilgün, B. E. K. (2014). Ayakkabı kullanımı ile ayak deformiteleri, denge ve fonksiyonel performans arasındaki ilişkinin incelenmesi. Journal of Exercise Therapy and Rehabilitation, 1(1), 35-42. ID: JA64ET77CG.

15. Hale, S. A., Hertel, J., Olmsted-Kramer, L. C. (2007). The effect of a 4-week comprehensive rehabilitation program on postural control and lower extremity function in individuals with chronic ankle instability. Journal of orthopaedic \& sports physical therapy, 37(6), 303311. Doi: 10.2519/jospt.2007.2322.

16. Hazar, Z., Ulug, N., \& Yuksel, I. (2014). Upper Quarter Y-Balance Test Score of Patients with Shoulder Impingement Syndrome. Orthopaedic journal of sports medicine, 2(11_suppl3), 2325967114S00275.

17. Koçak, U. Z., Ünver, B. (2019). Kadın futbolcularda yaralanma riski belirleyicileri olarak fonksiyonel hareket analizi ve y denge testi arasındaki ilişkinin incelenmesi. Spor Hekimliği Dergisi, 54(1), 001-008. Doi: 10.5152/tjsm.2019.110. 
18. Myers, H., Poletti, M., \& Butler, R. J. (2017). Difference in functional performance on the upper-quarter y-balance test between high school baseball players and wrestlers. Journal of sport rehabilitation, 26(3), 253-259.

19. Olmsted, L. C., Carcia, C. R., Hertel, J., Shultz, S. J. (2002). Efficacy of the star excursion balance tests in detecting reach deficits in subjects with chronic ankle instability. Journal of athletic training, 37(4), 501. PMID: 12937574.

20. Plisky, P. J., Rauh, M. J., Kaminski, T. W., Underwood, F. B. (2006). Star Excursion Balance Test as a predictor of lower extremity injury in high school basketball players. Journal of Orthopaedic \& Sports Physical Therapy, 36(12), 911-919. Doi: 10.2519/jospt.2006.2244

21. Plisky, P. J., Gorman, P. P., Butler, R. J., Kiesel, K. B., Underwood, F. B., Elkins, B. (2009). The reliability of an instrumented device for measuring components of the star excursion balance test. North American journal of sports physical therapy: NAJSPT, 4(2), 92. PMID: 21509114.

22. Roush, J. R., Kitamura, J., Waits, M. C. (2007). Reference values for the closed kinetic chain upper extremity stability test (CKCUEST) for collegiate baseball players. North American journal of sports physical therapy: NAJSPT, 2(3), 159. PMID: 21522211.

23. Salo, T. D., \& Chaconas, E. (2017). The Effect of Fatigue on Upper Quarter Y-Balance Test Scores in Recreational Weightlifters: A Randomized Controlled Trial. International journal of sports physical therapy, 12(2), 199.

24. Teyhen, D. S., Riebel, M. A., McArthur, D. R., Savini, M., Jones, M. J., Goffar, ve diğ. (2014). Normative data and the influence of age and gender on power, balance, flexibility, and functional movement in healthy service members. Military medicine, 179(4), 413-420.

25. Westrick, R. B., Miller, J. M., Carow, S. D., \& Gerber, J. P. (2012). Exploration of the y-balance test for assessment of upper quarter closed kinetic chain performance. International journal of sports physical therapy, 7(2), 139.

26. Wilson, L., Wright, S., \& Neza, D. (2013). The assessment of arm dominance in water polo players using the Upper Quarter Y Balance Test. In British Association of Sport and Exercise Sciences Conference (pp. 3-5). 